\title{
Determinants of Access to Entrepreneurial Credit: Examining Women Entrepreneurs in Sokoto State, Nigeria
}

\author{
Mulikat Folashade Usman $^{*} \quad$ Muhammad Kabir Kamba \\ Department of Business Administration, Faculty of Management Sciences, Usmanu Danfodiyo University, Sokoto
}

\begin{abstract}
This study was carried out to examine the determinants of women entrepreneurs' access to credit in Sokoto State of Nigeria. Primary data were obtained from a sample of 343 women entrepreneurs via questionnaire and analysed using binary logistic regression. Out of the seven factors investigated, only five were found to influence women entrepreneurs' access to credit in Sokoto State. These are cost of credit, collateral security, level of education, awareness of credit opportunities, and rigid terms and conditions. The other two, namely, credit union membership and proximity of credit facility were not found to influence women entrepreneurs' access to credit in Sokoto State. Results showed that level of education and awareness of credit opportunities were positively related to women entrepreneurs' access to credit whereas cost of credit, collateral security and rigid terms and conditions were negatively correlated with women entrepreneurs' access to credit. Findings suggest that microfinance institutions and other sources of credit facilities should reduce the cost of credit and the demand for collateral security as well as simplify the prevailing rigid terms and conditions so that women entrepreneurs in Sokoto State can access credit. Awareness of credit opportunities should be raised and women entrepreneurs should also be encouraged to improve their level of education in Sokoto State in order to leverage the credit faculties available to them. Moreover, policy makers and relevant stakeholders have the responsibility to make informed decisions to positively address the determinants identified in this paper.
\end{abstract}

Keywords: Access to Credit, Women Entrepreneurs, Logistic Regression, Sokoto State, Determinants DOI: $10.7176 / \mathrm{EJBM} / 11-8-12$

Publication date:March $31^{\text {st }} 2019$

\section{Introduction}

In the face of serious unemployment and poverty issues in Nigeria, many studies have identified entrepreneurship as the way forward. Although, entrepreneurship is not projected as a panacea for Nigeria's unemployment and underemployment problems, it recognised to create jobs and reduce poverty. The important role of Micro, Small and Medium Enterprises (MSMEs) in job creation and poverty reduction in Nigeria has long been recognized.

Entrepreneurs are however faced with many different problems, and access to finance has remained atop all other issues when it comes to translating entrepreneurial intentions to thriving businesses. In a 2013 National MSME Survey jointly conducted by the Small and Medium Enterprises Development Agency of Nigeria (SMEDAN) and National Bureau of Statistics (NBS), it was highlighted that one of the main challenges confronting the operations of MSMEs in Nigeria is access to finance. Other identified challenges include poor infrastructure, inconsistency in government policies, poor support (business development services), access to market, multiple taxation and obsolete technology. Undoubtedly, there are many people who are engaged in microenterprise businesses in Nigeria but need access to credit facility. Statistics showed the total number of MSMEs in Nigeria to be 37,067,416 with microenterprises accounting for almost $99 \%$ of them, and employing a total number of $59,741,211$ persons, representing $84.02 \%$ of the total labour force (SMEDAN and NBS, 2013). In spite of this substantial involvement of men and women in microenterprise activities in Nigeria, capital has always been an impediment to business growth and expansion of entrepreneurs (Olateju, 2018). As a result of the bottlenecks associated with accessing finance from conventional financial institutions, many entrepreneurs are often restricted to seeking microcredits, which are equally difficult to access. Evidence in literature suggests that women find it more difficult to access credit facilities than their male counterparts and this remains a huge challenge for women entrepreneurs in Nigeria (Nkamnebe, 2009).

The following questions were raised in this research work:

i. Is there is any relationship between cost of credit and access to credit in Sokoto State?

ii. Is collateral security a determinant of access to credit in Sokoto State?

iii. Is there any relationship between level of education and access to credit in Sokoto State?

iv. Is credit union membership a determinant of access to credit in Sokoto State?

v. Is there any relationship between awareness of credit opportunities and access to credit in Sokoto State?

vi. Is proximity of credit facility a determinant of access to credit in Sokoto State?

vii. Do rigid credit terms influence access to credit in Sokoto State?

To achieve this, this article is structured into five sections. Section one is the introduction, followed by the literature review and hypothesis development in section two. Section three presented the methodology. Section four discusses the results followed by the recommendations and conclusions which were drawn in section five 


\section{Literature Review and Hypothesis Development}

There are numerous factors that influence access to credit in the literature (Olateju, 2018; Kifle, Tadesse, Belay \& Yousuf, 2013; Peprah, 2012) including age of entrepreneurs, level of education, household size, number of years in business and income of the entrepreneurs. Some of the studies took on a gendered perspective and deployed various methods of analysis in different countries and locations but there is dearth of empirical works targeted at investigating the factors that contribute to lack of access to finance especially among women entrepreneurs in Sokoto State of Nigeria. It is therefore important to find out what factors influence access to credit among women entrepreneurs in Sokoto State of Nigeria. The aim of this research, therefore, is to determine the factors that influence women entrepreneurs' access to credit in Sokoto State.

Access to microfinance enables entrepreneurs to expand their businesses and produce more goods and services. Microfinance, which is used interchangeably with the term microcredit, is the provision of financial services to the economically active poor and low income households. When it was discovered that the poor had no access to traditional formal financial services, microfinance was introduced to provide services such as microcredit, savings opportunities, insurance, money transfer, micro-leasing and micro-insurance, to enable them engage in income generating activities. Microcredit was institutionalized in 1976 by Muhammed Yunus an American educated Bangladesh economist who had observed that a significant population of the world had been barred from acquiring capital necessary for poverty alleviation (Metu, 2017). The microfinance policy defines the framework for the delivery of financial services on sustainable basis to the micro, small and medium enterprises (MSMEs) through privately-owned microfinance banks. Microfinance is therefore designed mainly for entrepreneurs who are traditionally not served by the conventional financial institutions (CBN, 2005; Haruna, 2007).

Generally, extant literature reveals that different determinants of women entrepreneurs' access to finance have been examined in relation to country context with varying research designs. Sailot (2011) found business experience, size of business, educational level, age, and capital invested in the business to be factors that determine access to credit facility in Toi market, Nairobi County. In a study by Kifle et al. (2013), it was found that the amount of monthly savings of the client, size of the family, and number of land holdings in hectares are the factors that determine women's access to microfinance programme in Rural Dire Dawa-Ethiopia.

While investigating the determinants of women entrepreneurs' access to microcredit, Olateju, Aminu, Shehu, Danmola (2017) found that age, marital status, years of education, numbers of years of business experience, household size, membership of political party and income of the women entrepreneur were all significant predictors of women entrepreneurs' access to finance in Lagos, Nigeria. Examining these same variables for both men and women entrepreneurs in another study, Olateju (2018) found only four of these variables to be significant determinants of access to finance in Lagos among men and women entrepreneurs. These are age, number of years of education, political involvement and experience of the male entrepreneurs.

In an empirical analysis of the determinants of access to agricultural credit for small and marginal farmers in Dharwad district, Karnataka, India, Samuel, Isah and Patil (2015) analyzed cross-sectional-data from 120 respondents using logistic regression technique and found that landholdings, educational status, irrigation facilities, income level and gender are significant factors determining agricultural credit access of small and marginal farmers from banks. However, factors such as cost of credit, demand for collateral security, awareness of credit opportunities, proximity of credit sources, and rigid terms and conditions, which are perceived to influence women entrepreneurs' access to credit in Nigeria, were not examined in their study. Green (2003), in a study on credit guarantee schemes for small enterprises, found that rigid terms and conditions associated with credit accessibility are an inhibitor to access to credit.

Similarly, assessing the determinants of access to credit financial services by smallholder farmers in Kenya, Kiplimo, Ngenoh and Bett (2015) also deployed the logistic regression to find that "the marginal effects of education level, occupation and access to extension services were statistically significant with positive effects on access to credit financial services. However, total annual household income and the distance to the credit source were statistically significant with negative influence on access to credit financial services." Although, the study of Kiplimoh et al above examined the factors of education level and proximity to credit source among other variables, their study failed to investigate the contribution of cost of credit, collateral demand, awareness of credit opportunities as well as rigid terms and conditions to the log-odds of accessing credit especially among women entrepreneurs in Nigeria.

In Kenya also, Gichuki, Njeru and Tiramba (2014), carried out a study to determine the challenges facing micro and small enterprises in accessing credit facilities in Kangemi Harambee Market in Nairobi City County, Kenya. They analysed data collected from a sample of 241 MSEs using descriptive statistics and found that the key challenges hindering micro and small enterprises from accessing credit facilities in Kenya are high cost of repayment, strict collateral requirements, unwillingness of people to act as guarantors, high credit facilities' processing fees and short repayment period. However, this study by Gichuki et al failed to deploy techniques of 
inferential statistics and therefore lack the power of predictive generalization.

In Nigeria, Metu, Nwokoye \& Kalu (2015) had, in a related study, investigated the impediments to accessing finance for female micro entrepreneurs in Awka, Anambra State. Using bar charts and simple regression analysis, Metu et al found that lack of information, bottlenecks involved in accessing loan, high interest charged and stringent repayment terms are factors that significantly influence female micro entrepreneurs' access to finance in Awka, Nigeria.

In Nigeria also Wosowei (2015) examined the constraints to women entrepreneurs' access to microfinance services in Bayelsa State. Analyzing data collected from a sample of 150 respondents using descriptive statistics (mean scores) and exploratory factor procedure, she found that women entrepreneurs in Bayelsa State were faced with technical, management, economic, and social constraints in accessing microfinance services. In line with her findings, Wosowei recommended that reducing interest rate, relaxing strict conditions, bringing microfinance services closer to the people, and creating more public enlightenment for women entrepreneurs about microfinance services can improve access to microfinance services in the Bayelsa State.

Koko et al (2017) study of women entrepreneur's accessibility to growth capital and socioeconomic development in Sokoto State Nigeria, found that marital status, purdah, high semi- illiteracy and collateral requirement as significant determinant of accessibility to credit facility in Sokoto State.

Apparently, many factors influence entrepreneurs' access to microfinance. In the present study, therefore, we hypothesize that there is no significant relationship between cost of credit, collateral security, level of education, credit union membership, awareness of credit opportunities, proximity of credit facility and rigid terms and conditions and women entrepreneurs' access to credit in Sokoto State.

\section{Methodology}

The quantitative (descriptive) research design was adopted to quantify the relationships between access to credit and seven predictor variables in Sokoto State. A sample of 343 women entrepreneurs was selected from the population size of 3220 women entrepreneurs in Sokoto State using Krejcie and Morgan's (1970) sampling approach with a 95\% confidence level, 5\% margin of error and a population proportion of 0.5 . This is a standardised procedure in line with Krejcie and Morgan. Given that there are 23 Local Government Areas spread across 3 senatorial districts in Sokoto State, both purposive and stratified random sampling approaches were used to identify the target sample of 343 active women entrepreneurs in Sokoto State from whom primary data were obtained via questionnaire. Logistic regression was used to determine the relationship between the dichotomous characteristic of access to credit (AC) and a set of seven predictor variables, namely, cost of credit (CC), collateral security (CS), level of education (LE), credit union membership (CUM), awareness of credit opportunities (ACO), proximity of credit facility $(P C F)$ and rigid terms and conditions (RTC). We are therefore hypothesizing that women entrepreneurs' access to credit in Sokoto State is a function of seven factors. In order words,

$$
A C=f(C C, C S, L E, C U M, A C O, P C F, R T C)
$$

The cumulative logistic distribution function in a non-linear form is

$$
P(y)=\frac{1}{e^{-(\alpha+\beta X k)}}
$$

where y is the dependent variable representing women entrepreneurs' access to credit in Sokoto State. It takes on the value of 1 if women entrepreneurs have access to credit and 0 otherwise.

Equation (ii) does not allow for ease of interpretation of coefficients of variables, hence with a logit transformation, the estimated model becomes a linear function of the explanatory variables (Gujarati \& Porter, 2009 as cited in Metu, 2017). The logit transformation of the model is defined in terms of log-odds ratio as follows:

$$
\operatorname{Logit}[P(y)]=\ln \left(\frac{p}{1-p}\right)=\beta_{0}+\beta_{i} X_{k}
$$

where $\mathrm{P}(\mathrm{y})$ is the probability of women entrepreneurs accessing credit in Sokoto State; $\beta_{0}$ is a constant term; $\beta_{i}$ is a vector of coefficients of independent variables $X_{k}$, and $X_{k}$ is a vector of independent variables.

This is written in terms of our variables as follows:

$$
\text { Logit }[\mathrm{P}(\mathrm{AC})]=\beta_{0}+\beta_{1} C C+\beta_{2} C S+\beta_{3} L E+\beta_{4} C U M+\beta_{5} A C O+\beta_{6} P C F+\beta_{7} R T C
$$

Where:

$\mathrm{AC}=$ Access to credit

$\mathrm{CC}=$ Cost of credit

$\mathrm{CS}=$ Collateral security

$\mathrm{LE}=$ Level of education

CUM $=$ Credit union membership

$\mathrm{ACO}=$ Awareness of credit opportunities

$\mathrm{PCF}=$ Proximity of credit facility

$\mathrm{RTC}=$ Rigid terms and conditions

$\beta_{0}=$ constant or intercept 
$\beta_{1}-\beta_{7}=$ Estimated coefficients of predictor variables

Table 1: Description of Variables

\begin{tabular}{|l|l|l|l|}
\hline S/N & Variable Name & $\begin{array}{l}\text { Variable } \\
\text { Type }\end{array}$ & Variable Measurement \\
\hline 1 & Access to credit (AC) & Dummy & 1 - access; $0=$ no access \\
\hline 2 & Cost of credit (CC) & Continuous & 5-point likert scale \\
\hline 3 & Collateral security (CS) & Continuous & 5-point likert scale \\
\hline 4 & Level of education (LE) & Continuous & Number of years spent on education \\
\hline 5 & Credit union membership (CUM) & Dummy & $1=$ member; $0=$ not a member \\
\hline 6 & Awareness of credit opportunities (ACO) & Dummy & $1=$ aware; $0=$ no awareness \\
\hline 7 & Proximity of credit facility (PCF) & Dummy & $1=$ near; $0=$ not near \\
\hline 8 & Rigid terms and conditions (RTC) & Continuous & 5-point likert scale \\
\hline
\end{tabular}

\section{Results and Discussions}

A logistic regression was performed to determine the effects of cost of credit, collateral security, status of education, credit union membership, awareness of credit opportunities, proximity of credit facility and rigid terms and conditions on the likelihood that women entrepreneurs in Sokoto State have access to credit. Results are presented below.

\begin{tabular}{lcrr} 
& Table 2: Logistic Regression Results & & \\
\cline { 2 - 4 } Variable & Coefficient & P-value & Odds Ratio \\
\hline Cost of credit (CC) & $-0.635^{*}$ & 0.002 & 0.8801 \\
Collateral Security (CS) & $-0.504^{*}$ & 0.007 & 0.9183 \\
Level of education (LE) & $0.702^{*}$ & 0.04 & 1.0375 \\
Credit union memb.(CUM) & 0.032 & 0.890 & 1.1702 \\
Awareness (ACO) & $0.097^{*}$ & 0.006 & 1.0937 \\
Proximity of cred. fac. (PCF) & 0.001 & 0.201 & 1.5650 \\
Rigid terms \& cond. (RTC) & $-0.101^{*}$ & 0.044 & 0.9904 \\
Constant & $0.311^{* *}$ & 0.081 & \\
\hline
\end{tabular}

* Significant at 5\%;**Significant at $10 \%$

Number of observation $=343$

LR chi-square $(7)=57.14$

Prob $>$ chi-square $=0.0021$

Pseudo $\mathrm{R}^{2}=0.2927$

From the above Table 2, the fitted logistic regression model for our study of determinants of access to credit in Sokoto State is given as

$\ln \left(\frac{p(y)}{1-p(y)}\right)=0.311-0.635 C C-0.504 C S+0.702 L E+0.032 C U M+0.097 A C O+0.001 P C F-$ $0.101 R T C$

As indicated above, the logistic regression model was statistically significant at $5 \%$ level of significance, $\chi^{2}(7)=$ $57.14, p<.005$. This means that the seven determinants examined had a combined significant effect on women entrepreneurs' access to credit in Sokoto State. The model explained 29\% (Pseudo $R^{2}$ ) of the variance in access to credit. This predictive power is sufficient for a logistic regression model with a fairly large sample size as the one used in this study (Gujarati and Porter, 2009). When the predictor variables were evaluated for their individual contribution to the model, it was found that only 5 out of the 7 variables were significant in the model. The 5 variables are cost of credit, collateral security, level of education, awareness of credit opportunities, and rigid terms and conditions. The 2 variables with no significant contribution to the model are credit union membership and proximity of credit facility. These are explained below.

\section{Hypothesis 1 (H01): There is no relationship between cost of credit and access to credit}

Cost of credit and access to credit

Result of analysis in Table 2 indicates that there is a significant relationship between cost of credit and access to credit $(\rho=0.002<0.05)$ at the $5 \%$ level of significance. The null hypothesis $\left(\mathrm{H}_{01}\right)$ is therefore rejected. It was found that cost of credit was negatively correlated with women entrepreneurs' access to credit in Sokoto State. This means that if other variables are held constant, with a unit increase in cost of credit, the log odds of accessing credit would decrease by almost $63.5 \%$, and vice versa. Consistently, with an odds ratio of 0.8801 , a one unit increase in cost of credit would decrease the odds of accessing credit by a factor of 0.8801 . Cost of credit is therefore a negative determinant of accessibility of credit by women entrepreneurs in Sokoto State. This result is consistent with Gichuki, Njeru and Tiramba (2014) who identified high cost of repayment and high credit processing fees as challenges to accessing credit in Kenya. 


\section{Hypothesis 2 (H02): Collateral security is not a determinant of access to credit}

Collateral security and access to credit

Results in Table 2 show that the variable, collateral security, is a significant predictor of access to credit at the 5\% level of significance $(\rho=0.007<0.05)$. The null hypothesis $\left(\mathrm{H}_{02}\right)$ is therefore rejected. Collateral security was found to be negatively correlated with access to credit among women entrepreneurs in Sokoto State. A unit increase in the demand for collateral security decreases the log odds of accessing credit by $50.4 \%$ if other variables are kept constant. The odds ratio of 0.9183 shows that a one unit increase in the demand for collateral security decreases the likelihood of accessing credit by $91.8 \%$. Collateral security demand is a negative determinant of access to credit and is therefore a challenge to women entrepreneurs' capacity to access credit in Sokoto State. This result is also consistent with Metu (2017) and Gichuki, Njeru and Tiramba (2014). In particular, Gichuki et al identified strict collateral requirements as a challenge to accessing credit in Kenya.

\section{Hypothesis 3 (H03): There is no relationship between level of education and access to credit} Level of education (LE) and access to credit

Since $\rho=0.04<0.05$ in the Table 2 , we reject the null hypothesis $\left(\mathrm{H}_{03}\right)$ and conclude that there is a significant relationship between level of education and access to credit. Educational level of women entrepreneurs in Sokoto State was positively correlated with their likelihood of accessing credit. A unit change in their status of education increases their log-odds to access credit by almost $70.2 \%$ if other variables are kept constant. The odds of accessing credit increases by a factor of 1.0375 (or 104\% approximately) when there is a unit increase in level of education. This means that education a positive determinant of access to credit and is therefore critical to accessing credit in Sokoto State. This result is consistent with Sailot (2011), Samuel, Isah and Patil (2015) and Kiplimo, Ngenoh and Bett (2015). Particularly, Samuel et al. had found that education status was associated with access to agricultural credit in India while Kiplimo et al. found that higher level of education was positively correlated with proper understanding and completion of credit terms and documents as well as eventual access to credit.

\section{Hypothesis 4 (H04): Credit union membership is not a determinant of access to credit}

Since $\rho=0.890>0.05$ in the Table 2 , we do not reject the null hypothesis $\left(\mathrm{H}_{04}\right)$. Hence there is no sufficient evidence to say that credit union membership is a determinant of access to credit among women entrepreneurs in Sokoto State. This result is however at variance with Metu (2017) who reviewed that females have more access to credit facility from Esusu (an informal saving scheme where one contributes cash periodically and takes 'turn' to receive from the pool).

Hypothesis $5\left(H_{05}\right)$ : There is no relationship between awareness of credit opportunities and access to credit Awareness of credit opportunities (ACO) and access to credit

Results in Table 2 show that the variable, awareness of credit opportunities, is a significant predictor of access to credit at the $5 \%$ level of significance $(\rho=0.006<0.05)$. The null hypothesis $\left(\mathrm{H}_{05}\right)$ is therefore rejected. The variable, awareness of credit opportunities, was positively correlated with access to credit. A unit increase in the factor of awareness increases accessibility of credit by approximately $8 \%$ if other variables are kept constant. The odds ratio of 1.0937 shows that a one unit increase in awareness of credit opportunities increases the likelihood of accessing credit by approximately $109 \%$. Awareness is therefore a significant positive determinant of women entrepreneurs' access to credit in Sokoto State. This result is supported by Metu, Nwokoye \& Kalu (2015).

Hypothesis $6\left(\mathrm{H}_{06}\right)$ : Proximity of credit facility is not a determinant of access to credit

As evidenced in Table 2 with $\rho=0.201>0.05$, we do not reject the null hypothesis $\left(\mathrm{H}_{06}\right)$. Hence there is no sufficient evidence to say that proximity of credit facility is a determinant of access to credit among women entrepreneurs in Sokoto State.

Hypothesis 7 (H07): Rigid credit terms do not influence access to credit

Rigid terms and conditions (RTC) and access to credit

Results in Table 2 show that the variable, rigid terms and conditions, is a significant predictor of access to credit at the $5 \%$ level of significance $(\rho=0.044<0.05)$. The null hypothesis $\left(\mathrm{H}_{07}\right)$ is therefore rejected. The variable, rigid terms and conditions, was negatively correlated with women entrepreneurs' access to credit in Sokoto State. This means that if other variables are held constant, with a unit increase in the factor of rigid terms and conditions, the $\log$ odds of accessing credit would decrease by $10.1 \%$, and vice versa. Consistently, with an odds ratio of 0.9904, a one unit increase in the factor of rigid terms and conditions would decrease the odds of accessing credit by approximately $99 \%$. Cost factor of rigid terms and conditions are therefore a negative determinant of access to credit by women entrepreneurs in Sokoto State. This finding is supported by Green (2003) and Wosowei (2015).

\section{Conclusion and Recommendations}

Credit facility is important to women entrepreneurs as it helps to boost their entrepreneurial output in the society. However, there are factors that influence women entrepreneurs' access to credit. An empirical investigation of seven determinants of women entrepreneurs' access to credit in Sokoto State was carried out using logistic regression. The relationship between access to credit and the seven determinants, namely, cost of credit, collateral security, level of education, credit union membership, awareness of credit opportunities, proximity of credit facility 
and rigid terms and conditions, was examined. The study found 5 factors to be determinants of access to credit, namely, cost of credit, collateral security, level of education, awareness of credit opportunities, and rigid terms and conditions. Whereas, 2 factors, namely, credit union membership and proximity of credit facility were not found to be determinants of access to credit in Sokoto State at the 5\% level of significance. Of the 5 determinants, three factors were found to be negative, viz. cost of credit, collateral security and rigid terms and conditions. This means that these 3 factors are rather inhibitors to women entrepreneurs' access to credit in Sokoto State. However, level of education and awareness of credit opportunities were found to be positively related to access to credit.

Since women entrepreneurs' access to credit in Sokoto State is constrained by these 5 factors, microfinance banks, policy makers and other credit givers are advised to reduce the cost of credit and the demand for collateral security as well as simplify the prevailing rigid terms and conditions so that women entrepreneurs can access credit in Sokoto State. Similarly, awareness of credit opportunities should be raised and women entrepreneurs should also be encouraged to improve their level of education in Sokoto State in order to maximise the potentials of credit faculties.

It is suggested that further studies may be carried out to observe the effects of these determinants on the accessibility to credit of the male entrepreneurs in Sokoto State. in addition, others States in North-western Nigeria may be incorporated into future research.

\section{References}

Central Bank of Nigeria (CBN 2005). Microfinance policy, regulatory and supervisory framework. Abuja.

Gichuki, J. A. W., Njeru, A. \& Tirimba, O. I. (2014). Challenges facing micro and small enterprises in accessing credit facilities in Kangemi Harambee Market, Nairobi city, Kenya. International Journal of Scientific Research Publication, 4(12), 1-12.

Green, A. (2003). Credit Guarantee Schemes for Small Enterprises: An Effective Instrument to Promote Private Sector-Led Growth? SME Technical Working Paper No. 10. Vienna: UNIDO.

Gujarati, D. N. \& Porter, D. C. (2009). Basic Econometrics (5th ed.). New York: McGraw Hill.

Haruna, D. (2007, June). Microfinance: The financial system that works for the majority. Central Bank of Nigeria Microfinance Newsletter, 4.

Kifle1, D., Tadesse,Y., Belay, S., \& Yousuf, J.y (2013). Determinants of women's participation in microfinance services: empirical evidence from Rural Dire Dawa, Ethiopia. African Journal of Agricultural Economics and Rural Development 1 (1), 001-007.

Kiplimo, J., Ngenoh, E. and Bett, J. (2015). Evaluation of Factors influencing access to credit financial services: Evidence from small holder farmers in Eastern Region of Kenya. Journal of Economics and Sustainable Development, 6 (7): 97-106.

Metu, A. G., Nwokoye, E.S. \& Kalu, C. (2015). Investigating impediments to accessing finance by female micro entrepreneurs in Awka, Nigeria. In S. Igbatayo \& E. Ayodeji (Eds), Promoting finance of micro, small and medium enterprises in Nigeria (pp.257 - 274). Ado Ekiti: Afe Babalola University.

Metu, A. G. (2017). Challenges of accessing finance by female micro entrepreneurs in Anambra State, Nigeria (doctoral dissertation). Nnamdi Azikiwe Unversity, Awka, Nigeria.

Nkamnebe, A. D. (2009). Women and microcredit financing in Nigeria: Implications for poverty alleviation and fight against vulnerability. Paper presented at the Growing Inclusive Markets Conference at Dalhousie University, Halifax, Nova Scotia, Canada.

Olateju, O. A., Aminu, A. W., Shehu, A. \& Danmola, R. A. (2017). The determinants of women entrepreneurs' access to micro credit programme: A case study of Cowries Microfinance Bank (CMB) Lagos, Nigeria. International Journal of Development and Sustainability, 6(8): 783-791.

Olateju, O. A. (2018). Factors that Influence Men and Women Participation in Microcredit Programme in Lagos State, Nigeria: A Case Study of Cowries Microfinance Bank (CMD). European Scientific Journal, 14(13). Doi: 10.19044/esj. 2018.v14n13p75

Peprah, J. A. (2012). Access to micro-credit well-being among women entrepreneurs in the Mfantsiman Municipality of Ghana. International Journal of finance and banking studies, 1(1).

Sailot, K. (2011). A survey of the determinants of access to credit by women entrepreneurs in Toi market, Nairobi County. University of Nairobi Jomo Kenyatta Memorial Library. Retrieved: http://erepository.uonbi.ac.ke:8080/xmlui/handle/123456789/12615

Samuel, E., Isah, M. A. and Patil, B. L. (2015). The Determinants of access to Agricultural credit for small and Marginal Farmers' in Dharwad district, Karnataka, India. Research Journal of Agriculture and Forestry Sciences, 3(5), 1-5.

SMEDAN \& NBS (2013). Selected findings of collaborative survey. Retrieved from https://www.smedan.gov.ng/images/PDF/2013-MSME-Survey-Summary-Report.pdf

Wosowei, E. C. (2015). Constraints to women entrepreneurs' access to microfinance services in Bayelsa State, Nigeria. Research Journal of Finance and Accounting, 6(3), 67 -74. 